\title{
Comparison of continuous infusion and bolus administration of tramadol in postoperative children
}

\author{
Jeanne-Roos Tikoalu, MD; Darlan Darwis, MD; Bambang Madiyono, MD, PhD
}

\begin{abstract}
Objective To appraise the efficacy of tramadol therapy given by continuous infusion and bolus in handling child's postoperative pain that is mostly inadequate.

Methods This was a randomized, single-blinded clinical trial with parallel design. The study was done in the operation room, recovery room, pediatric intensive care unit, pediatric surgery, and pediatric ward of Cipto Mangunkusumo Hospital, Jakarta, Indonesia. There were sixty patients, 1-12 year-old, with elective operation between January and April 2002. Both groups received bolus of $2 \mathrm{mg} / \mathrm{kg}$ tramadol as an initial dose. Twenty-nine subjects received continuous infusion of $0.22 \mathrm{mg} / \mathrm{kg} / \mathrm{h}$ tramadol in 15 minutes afterwards. The other 31 subjects received the same boluses for every 6 hours. Before each tramadol administration, evaluation was done by observer using objective pain scale (OPS) and evaluation sheet that had been tested before the study. The study was done within 24 hours post surgery.

Results In the first 6 postoperative hours, mean total dose given by continuous infusion was significantly greater than that given by bolus ( $p=0.006$ ). On the contrary, mean total dose given within 24 hours by continuous infusion was significantly less than that given by bolus ( $p=0.037$ ). All subjects showed OPS result of ${ }^{3} 6$ in 0 minute. After that, the result decreased, except in 9 subjects it was still $>6$ in the $15^{\text {th }}$ minute. Vomiting was the commonest side effect.

Conclusion Continuous infusion of tramadol within 24 hours can be recommended as an analgesic in postoperative children [Paediatr Indones 2003;43:165-170].
\end{abstract}

Keywords: tramadol, postoperative children, continuous infusion, bolus, objective pain scale (OPS).

$\mathrm{P}$ ain is the most common cause of physiological and psychological stress and the most frequent reason why patients seek medical help. Treatment of pain in children is essential from both the ethical and the clinical aspects, and if inadequately treated it can produce serious emotional and affective disorders. ${ }^{1,2}$ Misconceptions about pain in children led to limited use of analgesic in children, particularly in postoperative children. ${ }^{3,4}$ Opioid analgesics have been used as analgesics in postoperative children. ${ }^{5}$

Tramadol is a centrally acting opioid analgesic which has been licensed for use on children older than 1 year of age in many European countries since 1977 and in USA since late 1980s. ${ }^{6}$ It acts at opioid receptors as a weak agonist and appears to modify transmission of pain impulses by inhibition of monoamineoxidase and norepinephrine reuptake, and also promotes serotonin release. ${ }^{7}$ Tramadol has a similar pharmacokinetic act in children who older than 1 year and adult, ${ }^{8}$ and continuous infusion of tramadol is better than bolus or pro re nata. ${ }^{9}$ This study aimed to appraise the efficacy of tramadol therapy given by continuous infusion and bolus in handling child's postoperative pain. We hypothesized that 24-hour tramadol consumption to overcome postoperative pain given by continuous infusion is less than given by bolus, as suggested by previous study. ${ }^{9}$

From the Department of Child Health, Medical School, University of Indonesia, Cipto Mangunkusumo Hospital, Jakarta.

Reprint requests to: Darlan Darwis MD, Division of Pediatric Intensive Care, Department of Child Health, Medical School, University of Indonesia, Cipto Mangunkusumo, Jakarta, Indonesia. Tel. 62-21-3144757, Fax. 62-21-3907743. 


\section{Methods}

Sixty children ( 39 boys and 21 girls), aged $1-12$ yearold, in ASA I and II who underwent general anesthesia and elective surgery at Cipto Mangunkusumo Hospital between January and April 2002, were recruited into this randomized single-blinded clinical trial with parallel design. The study started after obtaining the approval from The Committee of the Medical Research Ethics, Medical School, University of Indonesia and the informed consent from parents.

Sample size was calculated by hypotheses test of mean difference for independent variable to $30 \mathrm{pa}$ tients in each group. Patients were divided into 3 age categories $(1-<3$ years, $3-<6$ years, $6-£ 12$ years). Children that had taken tramadol within 30 days before the study, carbamazepine, or monoamineoxidase drugs, and those who had history of hypersensitivity to tramadol were not included in the study.

Premedication consisted of diazepam or dormicum had been given to 39 children in a few minutes before the operation. General anesthesia was comprised of elective pentothal induction and ventilation with nitrous oxide, oxygen, and halothane. No other analgesics or local anesthetics were given before or during the operation.

After the operation, children were assigned randomly to group I (continuous infusion group) or group II (bolus group). Both groups received bolus of $2 \mathrm{mg} /$ $\mathrm{kg}$ tramadol as an initial dose. Twenty-nine subjects received continuous infusion of $0.22 \mathrm{mg} / \mathrm{kg} / \mathrm{h}$ tramadol in 15 minutes afterwards. The other 31 subjects received the same boluses for every 6 hours. In case of necessity, repetitive boluses were given intravenously with attention to predicted plasma concentration drug at that time. Rescue analgesia of $0.1 \mathrm{mg} / \mathrm{kg}$ morphine was available if the subject did not achieve pain relief although maximum daily dose of tramadol $(12 \mathrm{mg} /$ $\mathrm{kg}$ ) had been attained. Subjects were withdrawn from the study for any of the following reasons: need of rescue analgesia, appearance of postoperative complications, or refusal of finishing the study. In this study, no subject necessitated termination.

In order to assess the efficacy of tramadol, we determined the intensity of pain at $0,15^{\text {th }}, 30^{\text {th }}, 60^{\text {th }}$, $180^{\text {th }}, 360^{\text {th }}, 720^{\text {th }}, 1080^{\text {th }}$, and $1440^{\text {th }}$ minute after recovery from anesthesia by using objective pain scale (OPS). OPS table consists of patient's blood pres- sure, weeping, movement, agitation, verbal evaluation, or body language. OPS score by means six or more than six was given as a cut off point for pain. Besides OPS table, evaluation had also been made by using evaluation sheet that consists of OPS score, doses and additional doses of tramadol, patient's activity, side effect of tramadol, and patient's vital sign. OPS table and evaluation sheet had been tested before the study.

All relevant data were collected in a special form. Data were processed and analyzed by using SPSS 10.0 version. Significance was tested by Student's $t$ test for independent data with normal distribution, Mann-Whitney U test for independent data with skewed distribution, and chi-square test for categorical data. Results were considered statistically significant if the $\mathrm{p}$ value was less than 0.05 .

\section{Results}

During the study period, 60 patients were enrolled which consisted of 29 patients of group I receiving tramadol by continuous infusion and 30 patients of group II receiving tramadol by bolus.

\section{Characteristics of subjects}

Most of the samples were children between $1-<3$ years $(23 / 60)$ and male patients outnumbered female in all age categories. The sample characteristics were given in Table 1 which shows that the groups were comparable.

\section{Tramadol consumption}

The tramadol doses that had been consumed by 60 subjects in this study can be seen in Table 2 .

The mean initial dose of tramadol consumption did not show significant difference between both groups $(p=0.178)$. After the first six postoperative hours, the mean total dose of tramadol consumption in group I was significantly more than that in group II \{47.1 (SD 21.03) mg vs. 33.3 (SD 15.34) mg; ( $p$ 0.006) $\}$. On the other hand, the mean total dose of tramadol consumption within 24 hours in group I was significantly less than that in group II \{103.2 (SD 46.12) mg vs. 133.3 (SD 61.37) mg; $p$ $0.037\}$. 
Jeanne-Roos Tikoalu et al: Comparison of continuous infusion and bolus of tramadol

Table 1. Characteristics of the subjects

\begin{tabular}{|c|c|c|}
\hline Subject characteristics & $\begin{array}{l}\text { Group I } \\
(n=29)\end{array}$ & $\begin{array}{l}\text { Group II } \\
(n=31)\end{array}$ \\
\hline Age $(y r)^{*}$ & 4.2 (SD 3.25) & 5.6 (SD 3.59) \\
\hline \multicolumn{3}{|l|}{ Sex } \\
\hline Male & 18 & 21 \\
\hline Female & 11 & 10 \\
\hline Weight $(\mathrm{kg})^{*}$ & 14.2 (SD 6.33) & 16.7 (SD 7.67) \\
\hline Height $(\mathrm{cm})^{*}$ & $101.3(S D 20.75)$ & $107.9(\mathrm{SD} 22.28)$ \\
\hline \multicolumn{3}{|l|}{ Vital signs* } \\
\hline Pulse (x/min) & $104.3(S D 7.48)$ & 103.7 (SD 6.77) \\
\hline Respiration (x/min) & $21.8($ SD 2.29) & 21.7 (SD 2.69) \\
\hline Mean Arterial Pressure $(\mathrm{mmHg})$ & $67.3(\mathrm{SD} 6.30)$ & 69.7 (SD 6.30) \\
\hline \multicolumn{3}{|l|}{ Previous operation } \\
\hline Yes & 10 & 14 \\
\hline No & 19 & 17 \\
\hline \multicolumn{3}{|l|}{ Have premedication } \\
\hline Yes & 20 & 19 \\
\hline No & 9 & 12 \\
\hline \multicolumn{3}{|l|}{ Premedication } \\
\hline Diazepam & 9 & 11 \\
\hline Dormicum & 11 & 8 \\
\hline Without premedication & 9 & 12 \\
\hline Duration of premedication (min)* & 16.7 (SD 8.56) & 14 (SD 5.3) \\
\hline \multicolumn{3}{|l|}{ Anesthesia } \\
\hline Pentothal, nitrous oxide, oxygen, halothane & 23 & 26 \\
\hline Nitrous oxide, oxygen, halothane & 6 & 5 \\
\hline Duration of anesthesia $(\mathrm{min})^{*}$ & 100 (SD 44.5) & $118.4(S D 51.21)$ \\
\hline Duration of operation $(\mathrm{min})^{*}$ & 103 (SD 72.6) & 109.8 (SD 50.83) \\
\hline
\end{tabular}

* Mean \pm SD(Standard Deviation)

Table 2. Mean doses of tramadol in both groups

\begin{tabular}{|c|c|c|c|}
\hline Variable & $\begin{array}{l}\text { Group I } \\
(n=29)\end{array}$ & $\begin{array}{l}\text { Group II } \\
(\mathrm{n}=31)\end{array}$ & $\mathbf{p}$ \\
\hline Initial dose & $\begin{array}{l}28.3 \text { (SD1 2.67) } \\
(23.7: 32.9)\end{array}$ & $\begin{array}{l}33.3 \text { (SD 15.34) } \\
(27.9 ; 38.7)\end{array}$ & 0.178 \\
\hline $\begin{array}{l}\text { Dose in } 15 \text { minutes } \\
95 \% \mathrm{Cl}\end{array}$ & $\begin{array}{l}18.7 \text { (SD 8.36) } \\
(16.7 ; 20.7)\end{array}$ & & \\
\hline Total dose 6 hours & $\begin{array}{l}47.1(\text { SD 21.03) } \\
(39.5 ; 54.7)\end{array}$ & $\begin{array}{l}33.3(\mathrm{SD} 15.34) \\
(27.9 ; 38.7)\end{array}$ & 0.006 \\
\hline 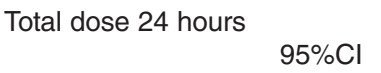 & $\begin{array}{l}103.2(\mathrm{SD} 46.12) \\
(86.4 ; 119.9)\end{array}$ & $\begin{array}{l}133.3(\mathrm{SD} 61.37) \\
(111.7 ; 154.9)\end{array}$ & 0.037 \\
\hline Total additional dose 6 hours & $\begin{array}{l}13.1 \\
(n=1)\end{array}$ & $\begin{array}{l}5.1(\mathrm{SD} 1.30) \\
(\mathrm{n}=2)\end{array}$ & NA \\
\hline Total additional dose 24 hours & $\begin{array}{l}13.1 \\
(n=1)\end{array}$ & $\begin{array}{l}5.1(\text { SD 1.30) } \\
(\mathrm{n}=2)\end{array}$ & NA \\
\hline
\end{tabular}

In the first six postoperative hours, all of 3 subjects who needed additional tramadol were in the 1 $<3$ years of age category and all of them had been done laparatomy. For the next 18 postoperative hours, no one needed additional dose.

Figure 1 depicts the mean dose of tramadol given to both groups. It can be seen that in the first 12 treatment hours, mean dose of tramadol needed on group I was equal with group II.

\section{Objective changes of postoperative pain}

In the beginning of the study, all subjects had OPS result $>6$ but it can be seen that the result decreased after both groups received tramadol. OPS results on $15^{\text {th }}$ minute showed that all subjects aged $6-<12$ years felt no pain anymore. However, there were 6 subjects aged $1-<3$ years and 3 aged $3-<6$ years still in pain. Most of the subjects were boys (7/9) with herniotomy 


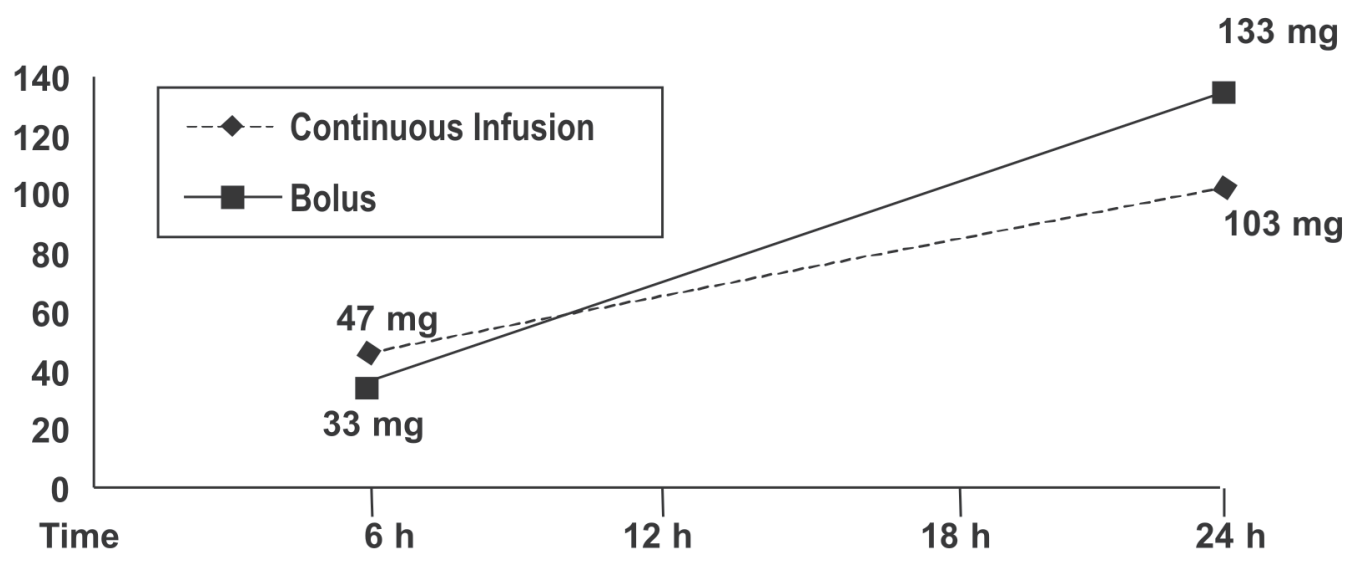

Figure 1. Mean dose of tramadol given to both groups

as the most frequent operation type (3/9). This operation was not the first for three out of that 9 subjects. OPS result in both groups on the next evaluation minutes was $<6$.

\section{Side effects}

No serious side effects were observed during the study and most of the subjects (47/60) had no side effects in using tramadol as an analgesic in postoperative children. The most frequently found side effect in this study was vomiting $(7 / 60)$, which was reported by 2 out of 29 subjects in group I compared with 5 out of 31 subjects in group II. The other observed side effects were nausea $(2 / 60)$, profuse sweating $(2 / 60)$, and vomiting with profuse sweating $(2 / 60)$.

\section{Discussion}

In this study, we found some limitations such as dissimilar premedication and general anesthesia since they depended on patient's condition and many children do not receive any premedication nowadays. Evaluation using OPS table and evaluation sheet could not be done by one researcher for the whole 24 hours so it influenced the subject's evaluation. Although there were plenty operations done in children, it was difficult to get the right sample because pain often exists during operation that the subject could not enroll the study.

Most of the subjects (19/29 and 17/31) never had operation before so it was assumed the OPS score revealed the true unpleasant experience for that operation, even though factors such as psychological, social, and cultural could not be avoided.

Both groups received bolus of $2 \mathrm{mg} / \mathrm{kg}$ tramadol as an initial dose. The group I received continuous infusion of $0.22 \mathrm{mg} / \mathrm{kg} / \mathrm{h}$ tramadol in 15 minutes afterwards. The group II received the same boluses for every 6 hours. These were based on the literature that recommended tramadol dose of $1-2 \mathrm{mg} / \mathrm{kg}$ for children older than 1 year ${ }^{12}$ which was also supported by previous study. ${ }^{13}$

It had been predicted that in the first 12 hours of tramadol administration (Figure 1), the amount of doses needed for those 2 groups was the same. Regarding that $75 \%$ postoperative children complain of having extreme pain on the operation day and 17\% are still in pain on the first postoperation day, ${ }^{14}$ tramadol given within 24 hours by continuous infusion is recommended to be used as an analgesic in postoperative children over 1 year of age. ${ }^{13}$

According to tramadol pharmacokinetic study given parenterally in children, this medicine should be used between 1 and 2 days for reaching a steady state of tramadol within 1 to 2 days. ${ }^{8}$ In this study, children in the $6-<12$ years of age category reported that they felt comfortable and painless for 2 days after the first tramadol administration.

Before the initial loading dose administration $(0$ minute), both groups had OPS results of $>6$ which means that the subjects felt pain. It refers to the literature $^{14}$ that postoperative patients will feel pain and need analgesia.

In the minutes after tramadol administration, the OPS result decreased. It proved that tramadol had a 
11. Latief SA, Suryadi KA, Dachlan MR. General anesthesia (Anestesia Umum). In: Practical guideline (Petunjuk praktis) of Anesthesiology (Anestesiologi). 2nd ed. Jakarta: Department of Anesthesia and Intensive Therapy; 2002. p. 27-96.

12. Lee CR, McTavish D, Sorkin EM. Tramadol. A preliminary review of its pharmacodynamic and pharmacokinetic properties, and therapeutic potensial in acute and chronic pain states. Drug 1993;46:313. 40.

13. Klarinski K, Dluholucki S, Laho S. Treatment of pain with tramal in children above one year of age. Cs Pediatr 1994;3:169-71.

14. Binda RE, Mestad PH. Anesthetic considerations. In: Ashcraft KW, Holder TM, editors. Pediatric surgery. 2nd ed. Philadelphia: Saunders; 1993. p. 42-9.

15. Griessinger N, Rosch W, Schott G, Sittl R. Tramadol infusion for pain therapy following bladder exstrophy surgery in pediatric ward. Urologe A 1997;36:552-6.

16. Barsoum MW. Comparison of the efficacy and tolerability of tramadol, pethidine and nalbuphine in children with postoperative pain. Clin Drug Invest. 1995;9:183-90.
17. Wilder-Smith $\mathrm{CH}$, Bettiga A. The analgesic tramadol has minimal effect on gastrointestinal motor function. Br J Clin Pharmacol 1997;43:1-5.

18. Liebelt E, Levick N. Acute pain management and sedation in children. In: Tintinalli JE, Kelen GD, Stapczynski JS, editors. Emergency medicine. A comprehensive study guide. 5th ed. New York: McGrawHill; 2000. p. 890-9.

19. Houmes RJ, Voets MA, Verkaaik A, Erdmann W, Lachmann B. Efficacy and safety tramadol versus morphine for moderate and severe postoperative pain with special regard to respiratory depression. Anesthesia and Analgesia 1992;74:510-4.

20. Cossmann M, Wilsmann KM. Effect and side effects of tramadol. Therapiewoche 1987;37:1-10. (Citation from: Lee CR, McTavish D, Sorkin EM. Tramadol. A preliminary review of its pharmacodynamic and pharmacokinetic properties, and therapeutic potensial in acute and chronic pain states. Drug 1993;46:313-40.)

21. Henzi I, Walder B, Tramer MR. Metoclopramide in the prevention of postoperative nausea and vomiting: a quantitative systematic review of randomized, placebocontrolled studies. Br J Anaesth 1999;83:761-71. 
good efficacy as an analgesia which was also supported by previous studies. ${ }^{6-8,13,15-17}$

OPS result decreased especially at $15^{\text {th }}$ minute after the administration. It is indirectly in accordance with the literature that mean peak plasma concentration of tramadol in children can be reached within 8 to 15 minutes. ${ }^{18}$

Postoperative pain in 15 minutes after receiving tramadol could still happen remembering that there were parts of evaluation where researcher's subjectivity played a big deal, besides most of the subjects (6/9) were in the $1-<3$ years of age category. It should be noted that the $15^{\text {th }}$ minute's evaluation was done before we started the continuous infusion.

Maximum dose of tramadol for children is 12 $\mathrm{mg} / \mathrm{kg} .{ }^{16}$ In this study, all subjects did not need the maximum dose, almost all subjects felt that pain decreased with recommended dose.

With the given dose, most subjects (47/60) did not suffer from the side effects, which was similar with previous studies. $6,9,12,13,19,20$ The commonest side effect was vomiting $(7 / 60)$ that occurred in postlaparatomy patients due to the effect of intraabdominal organ manipulation. This finding is different from other study, ${ }^{20}$ which showed that irritation in the center nerve system, such as dizziness, drowsiness, and tremor, happened in $6.5 \%$ of their 13,802 patients who received tramadol. Vomit could be overcome by using metoclopramide $0.1 \mathrm{mg} / \mathrm{kg}$ although other study recommended giving $0.25 \mathrm{mg} / \mathrm{kg}$. ${ }^{21}$

On monitoring subjects who had side effect, we observed that side effects could happen soon after rapid administration of tramadol either with continuous infusion or bolus as reported by Lee et al. ${ }^{12}$ Nevertheless, this condition can be avoided by giving it slowly.

In conclusion, although both administration routes are good methods for postoperative pain relief, mean total dose of tramadol consumption given by continuous infusion within 24 hours is significantly less than that of given by bolus. We recommended the usage of tramadol within 24 hours by continuous infusion as an effective analgesic in postoperative children. We also recommended giving analgesia as soon as possible after the operation. In spite of vomiting as the commonest side effect, tramadol has relatively no significant side effects. We suggested a double-blinded clinical trial to observe the efficacy of tramadol in only one type of operation or the efficacy of tramadol as a preemptive treatment.

\section{Acknowledgements}

We express our sincere thanks and gratefulness to all the participated children and their parents, all colleagues, and nursing staffs from the Department of Anesthesia and Department of Surgery for their cooperation and invaluable work. We also indebted to Arini Setiawati PhD, Prof. Sudigdo Sastroasmoro MD $\mathrm{PhD}$, Suryanto H MD, and Dewi RS MPH for their contribution in the study.

\section{References}

1. Hamill RJ. The physiologic and metabolic response to pain and stress. In: Hamill RJ, Rowlingson JC, editors. Handbook of critical care pain management. New York: McGraw-Hill; 1994. p. 39-52.

2. Desborough JP. The stress response to trauma and surgery. Br J Anaesth 2000;85:109-17.

3. Sellman GL. Pain management in children. In: Behrman RE, Kliegman RM, Nelson WE, Vaughan VC, editors. Nelson's textbook of pediatrics. $14^{\text {th }} \mathrm{ed}$. Philadelphia: Saunders; 1992. p. 249-52.

4. Petrack EM, Christopher NC, Kriwinsky J. Pain management in the emergency department: patterns of analgesic utilization. Pediatrics 1997;99:711-4.

5. Boysen PG, Blau WS. Pain management and sedation in the intensive care unit. In: Gallagher TS, editor. Postoperative care of the critically ill patient. Baltimore: Williams \& Wilkins; 1995. p. 67-86.

6. Moore RA, McQuay HJ. Single-patient data metaanalysis of 3453 postoperative patients: oral tramadol versus placebo, codein and combination analgesics. Pain 1997;69:287-94

7. Lewis KS, Han NH. Tramadol: a new centrally acting analgesic. Am J Health-Syst Pharm 1997;54:643-52.

8. Murthy BV, Pandya KS, Booker PD, Murray A, Lintz W, Terlinden R. Pharmacokinetics of tramadol in children after i.v. or caudal epidural administration. Br J Anaesth 2000;84:346-9.

9. Rud U, Fisher MV, Mewes R, Paravicini D. Postoperative analgesia with tramadol. Continuous infusion versus repetitive bolus administration. Anaesthesist 1994;43:316-21.

10. Brown TCK, McKenzie IM. Anesthesia for infants and children. In: Prys-Roberts C, Brown BR, editors. International practice of anesthesia. Successor to general anesthesia. Oxford : Butterworth - Heiwemann; 1996. p. 2/104/1-14. 